
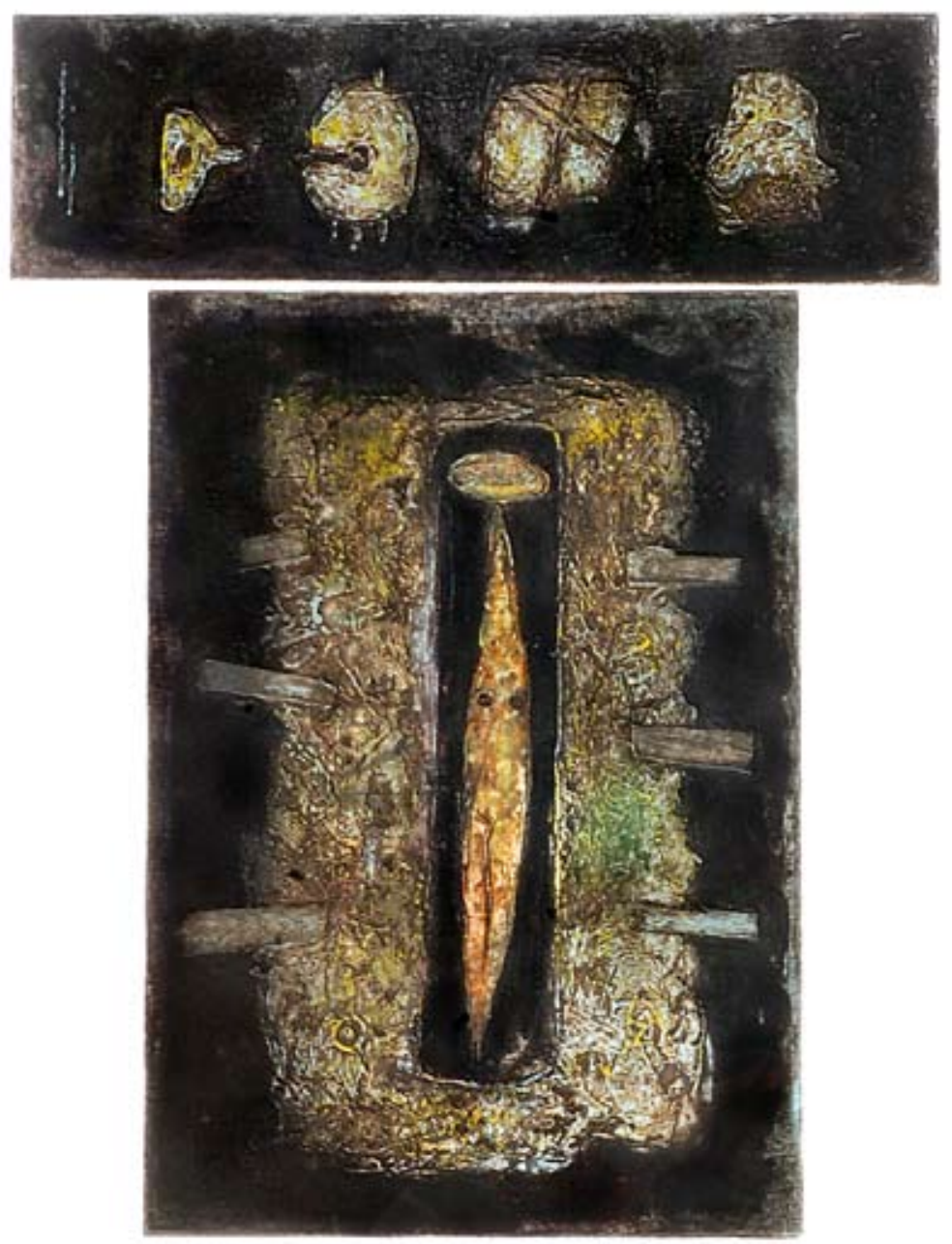

“Pachamama”, collagraph. Marta Arangoa 


\section{La calidad de la educación está condicionada por la calidad de nuestros profesores}

Maria Graciela DI FRANCO

$\mathrm{L}$ a reforma educativa encaminada bajo la prescripción del Plan Maestro plantea como argumento central que la calidad de la educación está directamente condicionada por la calidad de nuestros profesores. Los fundamentos que sostienen esta idea así como la lógica de la reforma se asientan en una concepción economicista de la educación desde la que se definen políticas públicas y el sentido de la formación.

Uno de los referentes teóricos que abrevan en el Plan Maestro ofrece argumentos para comprender en profundidad el sentido de la reforma. Nos referimos al libro de Bárbara Bruns y Javier Luque Profesores excelentes: Cómo mejorar el aprendizaje en América Latina y el Caribe (2015), publicación de la Serie del Foro sobre Desarrollo de América Latina, Grupo Banco Mundial. El título de esta Editorial es la transcripción de su sentido pleno.

Desde el prólogo del libro, los autores señalan que durante gran parte de la última década los países de América Latina y el Caribe fueron protagonistas de un avance social $\sin$ precedentes.

Casi 80 millones de personas salieron de la pobreza; más de 50 millones pasaron a formar parte de la clase media; la cobertura de la educación primaria se volvió prácticamente universal, y la cantidad de años de escola- rización promedio se ha acercado al valor de los países de la Organización para la Cooperación y el Desarrollo Económicos (OCDE) (...) el principal factor del aumento de los ingresos ha sido el crecimiento económico, que se traduce en reducción de la pobreza y prosperidad compartida para más personas. (2015, p. XVII)

Indican, además, que la desaceleración económica de los últimos años ha puesto en duda la sostenibilidad del avance logrado en la década pasada para lo cual la región debe formular sus propias estrategias para lograr una producción más diversificada, exportaciones de mayor valor y crecimiento sostenible a largo plazo. Para ello argumentan como fundamental la formación del capital humano, ingrediente principal de una mayor productividad e innovaciones aceleradas, como desafío central para la región. Este grupo de autores inician una investigación presentada en el documento cuyos objetivos son:

Medir el desempeño actual de los profesores de América Latina y el Caribe respecto de parámetros establecidos e identificar las principales dificultades; compartir la evidencia más reciente sobre las reformas a las políticas docentes que se están implementando en distintos países de la región; analizar el 
margen político para aplicar más reformas en la región. (2015, p.1)

El estudio se centra en los profesores de educación básica (preescolar, primaria y secundaria) y en los sistemas educativos públicos porque "continúan siendo los guardianes de la calidad de la educación y los arquitectos de las políticas educativas" (p.2).

\section{La importancia de los profesores}

Se reconoce en el documento que la calidad de los profesores impulsa el aprendizaje y allí se preguntan: ¿Quiénes son los profesores de América Latina y el Caribe? La descripción incluye que en su mayoría son mujeres, de posición socioeconómica relativamente baja; elevados niveles de educación formal, pero escasas capacidades cognitivas; con salarios relativamente bajos y trayectoria plana del salario compensada por la estabilidad laboral. Señalan, además, una oferta excesiva de programas de educación superior (terciarios) de formación docente con un considerable exceso de graduados docentes con un nivel académico generalmente bajo. (p.11)

\section{Los profesores \\ latinoamericanos en el aula}

En el documento se ofrece una mirada al desempeño de los profesores dentro del aula en siete países de la región. De los indicadores seleccionados se informa sobre el escaso uso del tiempo de instrucción como principal contribuyente al bajo aprendizaje de los alumnos en la región. A su vez, plantean que los profesores utilizan profusamente el pizarrón y recurren poco a las tecnologías de la información y las comunicaciones. Por su parte, los estudiantes no participan, las prácticas promedio dentro del aula varían enormemente de una escuela a otra y las prácticas de clase varían enormemente dentro de una misma escuela.

\section{Reclutar mejores profesores}

En el documento se señala que para mejorar la calidad de los profesores se deben afrontar tres desafíos básicos: reclutar, desarrollar y motivar mejores profesores. Para ello proponen incrementar la selectividad, elevar los parámetros para el ingreso a los programas de educación docente, así como también la calidad de la educación de los profesores y los estándares de contratación. A su vez, aumentar la selectividad en la docencia en los próximos diez años.

\section{Desarrollar profesores de excelencia}

El documento avanza con las modalidades aportadas desde la investigación sobre cómo el sistema escolar se responsabiliza de que los profesores sean lo más eficaces posible. Esto implica cuatro tareas:

- Inducción: en el desempeño inicial docente los sistemas escolares tienen una valiosa oportunidad para respaldar y maximizar el desarrollo de los nuevos profesores y detectar a aquellos a los que se les debería sugerir dejar la profesión.

- Evaluación: sistemas para la evaluación periódica de los puntos fuertes y débiles de cada profesor a fin de mejorar la calidad de los profesores y lograr que rindan cuentas por su desempeño.

- Desarrollo profesional: capacitación eficaz para subsanar las debilidades detectadas (por ejemplo la capacitación en servicio surge como uno de los principales elementos del gasto educativo en América Latina y el Caribe) y potenciar las capacidades de cada docente. Mencionan para esto: métodos de instrucción "con guión"; dominio de contenidos; gestión del aula; colaboración entre colegas.

- Asignación y gestión de los profesores: el desarrollo y mejora de las capacidades de los profesores es responsabilidad directa de los directores de las escuelas. Se busca conformar escuelas eficaces mediante la práctica compartida y la interacción profesional.

\section{Motivar a los profesores para que mejoren su desempeño}

Para lograr avances concretos y elevar la calidad de los profesores de América Latina y el Caribe, será necesario atraer a candidatos de alto nivel, separar continua y sistemáticamente de sus cargos a quienes demuestren el 
desempeño más bajo, y motivar a las personas para que continúen refinando sus capacidades y trabajando duro durante una larga carrera. Vegas y Umansky (2005, p.40) establecen un marco integral de incentivos que se pueden agrupar en tres categorías amplias: a) recompensas profesionales, como satisfacción intrínseca, reconocimiento y prestigio, crecimiento profesional, dominio intelectual y condiciones de trabajo agradables; b) presión por rendir de cuentas y c) incentivos financieros.

\section{Gestionar el aspecto político de las reformas docentes}

En este apartado se analiza el papel destacado de los sindicatos docentes en la región y las experiencias recientes de varios países con grandes reformas educativas. Al respecto argumentan que los sindicatos docentes han sido, históricamente, una fuerza progresista que ha logrado la igualdad de ingreso y el tratamiento equitativo para las mujeres y los miembros minoritarios. Pero también es cierto que los objetivos de las organizaciones docentes no son congruentes con los objetivos de los encargados de la formulación de políticas educativas ni con los intereses de los beneficiarios de la educación, incluidos estudiantes, padres y empleadores que requieren trabajadores calificados. (p.48)

Luego del análisis de algunas propuestas implementadas afirman, con "la evidencia disponible", que la limitación más importante del avance de los sistemas educativos es la calidad de los profesores.

El documento se concluye con la siguiente afirmación: ningún programa de preparación docente hoy está preparado para el perfil docente actual, ni para el que se necesitara en los próximos diez años. Se piensa en un docente que debería dotar a los estudiantes de herramientas para buscar, analizar y usar adecuadamente vastas cantidades de información que está disponible por otros medios. Se debe ayudar a que los estudiantes desarrollen competencias en una amplia gama de esferas valoradas en una economía mundial integrada por: pensamiento crítico, resolución de problemas, capacidad para el trabajo colaborativo en distintos entornos, adaptación al cambio y capacidad para dominar nuevos conocimientos, capacidades y las cambiantes demandas del empleo a lo largo de sus vidas. (p.50)
Todo el libro aportar argumentos para cuantificar el gran impacto económico de la calidad de los profesores.

También para nosotras es central pensar que la calidad de la educación está condicionada por la calidad de nuestros profesores, pero ubicada política, ideológica y éticamente en la buena enseñanza. Pensamos en una formación radicalmente distinta, orientada por las buenas prácticas (Fenstermacher, 1989 y Litwin, 2012), en los profesores memorables y ejemplares y en sus construcciones, con una concepción democrática del poder, de la circulación de saberes y de inclusión. A su vez, pensamos en un estado garante de la educación como derecho y no como un gasto y un servicio a pagar. Un estado que asume la responsabilidad de educar indelegable en el mercado.

Ken Bain, quien en su libro caracteriza las prácticas de algunos de los mejores profesores de su país e indaga acerca de qué hacen y cómo piensan los denominados por sus alumnos como "profesores extraordinarios» señala que:

Conocen su materia extremadamente bien... son consumados eruditos, artistas o científicos en activo... están al día de los desarrollos intelectuales, científicos o artísticos de sus campos, razonan de forma valiosa y original en sus asignaturas, estudian con cuidado y en abundancia lo que otras personas hacen en sus disciplinas, leen a menudo muchas cosas de otros campos y ponen mucho interés en los asuntos generales de sus disciplinas: la historia, controversias y discusiones epistemológicas. (2007, pp.26-27)

Los buenos docentes "empujan" a los estudiantes hacia "objetivos de aprendizaje" y hacia una "orientación de dominio" y no de resultado, mostrando "gran interés en su aprendizaje" $\mathrm{y}$ "fe en sus capacidades", ofreciendo también "realimentación exenta de valoración". (Bain, 2007, p.47)

Preferimos ubicarnos en esta concepción dado que en nuestra experiencia de indagación descubrimos que no hay una sola forma sino muchas de desplegar el "oficio de enseñar" (Litwin, 2012, p.13). Pero no es en el mercado, las mediciones, el control, el miedo, la gestión economicista lo que adjetiva de excelentes a nuestras/os profesoras/es, sino su capacidad 
política de advertir en la escolaridad la mejor manera de generar bolsillos de resistencia, capaces de construir argumentos para vivir mejor y poder pensar con autonomía moral e intelectual. Al respecto, los artículos de este número nos ayudan a pensar esta perspectiva política.

\section{Notas bibliográficas}

Bain, K. (2007). Lo que hacen los mejores profesores universitarios. Barcelona: Universidad de Valencia.

Bruns, B. y Luque, J. (2015). Profesores excelentes: Cómo mejorar el aprendizaje en América Latina y el Caribe. Cómo mejorar el aprendizaje en América Latina y el Caribe. Serie del Foro sobre Desarrollo de América Latina; Grupo Banco Mundial. La presente obra fue publicada originalmente por el Banco Mundial en inglés como Bruns, Barbara, y Javier Luque (2015), Great Teachers: How to Raise Student Learning in Latin America and the Caribbean, doi:10.1596/9781-4648-0151-8, Washington, DC, Banco Mundial. Licencia: Creative Commons de Reconocimiento para Organizaciones Intergubernamentales CC BY 3.0 IGO. En caso de discrepancias, prevalecerá el idioma original.

Fenstermacher, G. (1989). Tres aspectos de la filosofía de la investigación sobre la enseñanza. En M. Wittrock (Comp.). La investigación de la enseñanza I. Enfoques, teorías y métodos. (pp.149-179). Barcelona: Paidós.

Freire, P. (2014) El Grito Manso. $9^{\circ}$ edición Siglo XXI. Buenos Aires, 2014

Litwin, E. (2012). El oficio de enseñar. Buenos Aires: Paidós

Maggio, M. (2012) Conferencia Profesores ejemplares: prácticas memorables y perspectivas de futuro. Organización de los Estados Iberoamericanos, Buenos Aires, 26 de Junio 2012.

Souto, M. (2016). Pliegues de la formación. Santa Fe: Homo Sapiens.

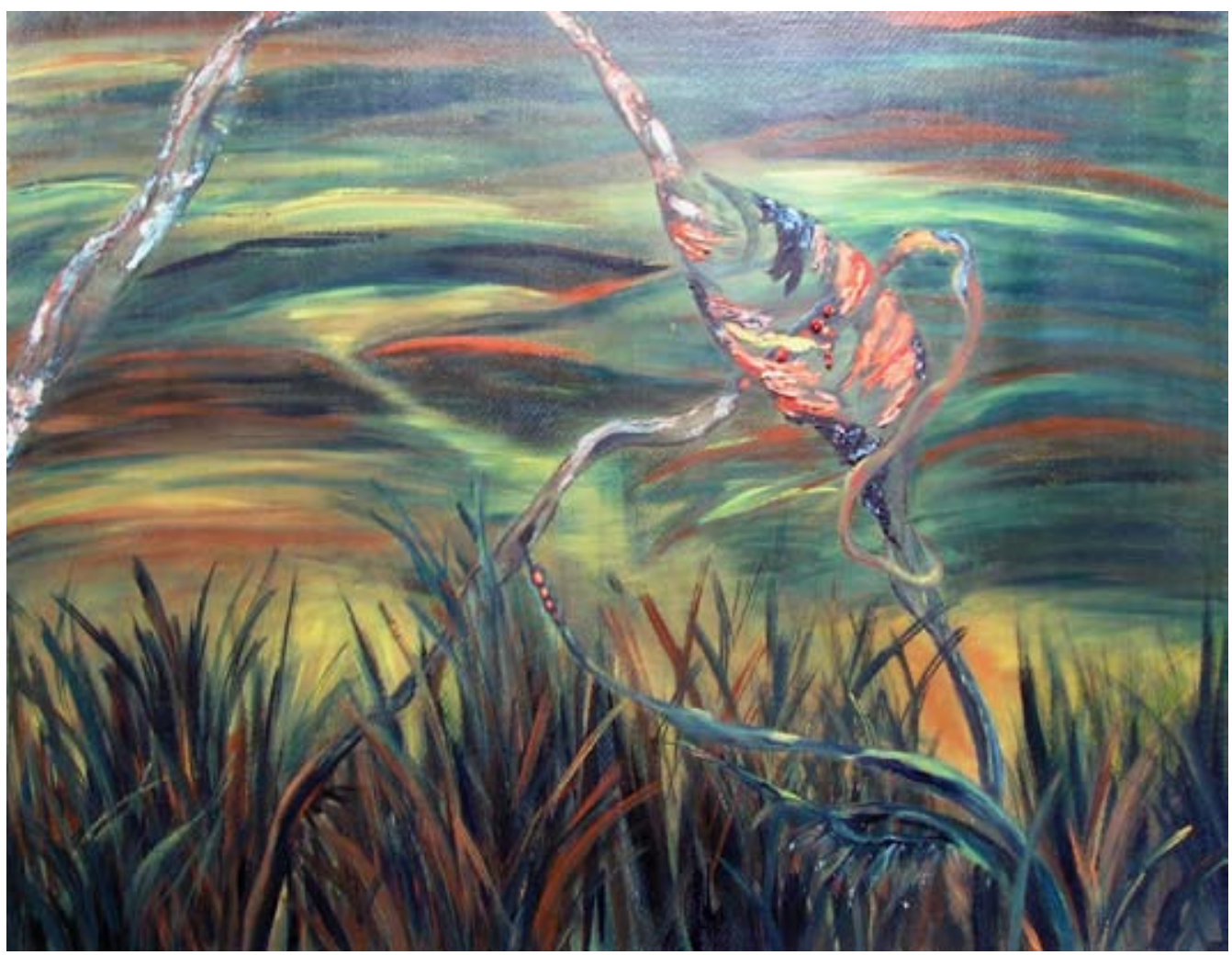

“Enredo en la noche”, acrílico. Carola Ferrero 